\title{
THE DEVELOPMENT OF TEAMS IN THE CONTEXT OF LEARNING BASED ORGANIZATIONS
}

\author{
Ştefania BUMBUC \\ "Nicolae Bălcescu" Land Forces Academy, Sibiu, Romania \\ stefanabumbuc@gmail.com
}

\begin{abstract}
In learning organizations, whether we are referring to educational institutions or to organizations from the labour market that work with information, generate and organize knowledge in different areas, teamwork has in fact become team learning. The present paper aims to analyze some classic explanatory models of the stages and non-stages type of team development, this analysis being carried out in the specific context of the learning organizations. The methodological approach belongs to the area of content analysis and synthesis, consisting in identifying and interpreting elements of theoretical models of team development that could become problematic in the context of team learning.
\end{abstract}

\section{Keywords: team learning, stages evolution, non-stages evolution}

\section{Introduction}

The specialized literature on teamwork is particularly rich. If in the past few years the number of editorial publications related to the group has diminished, the interest in the team increased, as a privileged way of achievement and personal development. In organizations from the modern world and, in general, on the current labour market, teamwork is considered to be the most fruitful and effective approach of learning activities, decision making and leadership. In recent studies, the emphasis is on optimizing interactions, on normalizing conduct, on making joint decisions, on leadership style, or on managing conflicts.

In learning organizations, whether we are referring to educational institutions or to organizations from the labour market that work with information, generate and organize knowledge in different areas, teamwork has in fact become team learning. A teamwork researcher, Jean Proulx, offers a very good introduction to this issue, stating that in knowledge-based organizations "teamwork is a time-limited learning activity, whereby two or more people learn how to perform more or less structured tasks, together and in an interactive way, in order to achieve certain objectives" [1]. The specificity and dynamics of teams that learn in this type of organizations can be studied according to several classical explanatory models, which allow additions and flexible approaches, as well as a deeper explanation of contemporary organizational phenomena.

\section{Aim and methods}

The present paper aims to analyze some classic explanatory models of the stages and non-stages type of team development, this analysis being carried out in the specific context of the learning organizations. The methodological approach belongs to the area of content analysis and synthesis, consisting in identifying and interpreting elements of 
theoretical models of team development that could become problematic in the context of team learning.

\section{Stages models of team development}

Classical theoretical models describing the stages of a team development explain the team's transformations by going through successive phases on the time axis, characterized by quantitative accumulations and qualitative improvements of activity, inevitably followed by team breakdown and cessation of activity.

One of the first explanatory models of team development is probably the one created by Waren Bennis and Herbert Shepard [2]. Starting from the idea of the authors, we can say that the evolution of a team towards maturity has a similar trajectory to the learning process: spiralling, ascending, but with apparent stagnation and resurrection, with periodical replay of the same themes, obstacles and problems, which are solved more and more efficiently. Accordingly, the two-phase model was developed to describe the evolution of the teams, from constitution to maturity and performance in learning [3]: (a) dependence on the leader, where learning process depends on the configuration of power relations. The team moves from passive submission to rebellion against authority and leader ideas, and finally takes the leader's integration as a member of the group, together with the acceptance of shared responsibility. (b) interdependence between members and the leader, where the functioning of the team depends on interpersonal relationships. After a common state of well-being and cohesion, the team atmosphere becomes tense under the pressure of the deadline and learning outcomes expectations. The group members conclude that it is necessary to involve everyone in the task and to assume individual responsibilities. In this way, the maturity of the team is achieved, characterized by the mutual recognition of the members' value, by the feelings of fulfilment generated by the learning process and the knowledge accumulation.

Probably the most known and evoked theoretical model of a team development is the one created by Bruce W. Tuckman [4], who later collaborated with Mary Ann Jensen, the stages identified by them being the following: (a) forming is a moment of mutual exploration, in which information and resources are acquired; (b) storming is the stage of confrontation regarding team trajectory, assignment of roles and tasks; (c) norming corresponds to the moment of elucidation of problems, the emergence of consensus, the assumption of some behavioural norms; (d) performing is the stage where the team is focused on the actual achievement of learning tasks, through efforts and interactions, by capitalizing on competencies; (e) adjourning is the stage of team disintegrating, in which members provide mutual emotional support, participate together in highlighting the success, and prepare for new projects.

\section{Non-stages models of team development}

In organizational studies, also the nonstages theoretical models of development have appeared, explaining the evolution of the teams according to various important parameters in the course of the learning activities, without identifying evolutionary stages of qualitative progress of the activity. A reference model is that proposed by Bernard M. Bass and Edward R. Ryterband [5], who state that not all groups go through multiple stages, some remaining stuck in certain types of activities and relationships specific to the beginning. However, if each member and also the group as a whole gradually learn how to efficiently use their resources, they go through a series of stages that are not considered qualitative leaps, but only transformations in the learning process: (a) mutual acceptance - the issues related to the compatibility of the members are cleared, a trustworthy situation is 
established, the position of the leader is strengthened, the group relations network is set up, exchanges of information and mutual testing of knowledge and experience take place; (b) communication and decision making - an effective mechanism for collective decision-making is created, team members feel free to present their attitudes towards certain issues, the rules are set, people discuss goals and assignments; (c) motivation and productivity - group members are now united, motivated and engaged in team learning, they cooperate and work hard, feelings of satisfaction appear; (d) control and organizing - each person can value his/her capabilities, contributing from different directions to the learning task of the group and being able to mutually compensate other people liabilities. Larger efforts are being made in terms of organizing intellectual work, and the informal activities of the group are frequent.

A study published by Joseph McGrath [6] highlights the idea that different teams could follow different development paths to reach the same outcome. TIP (time, interaction, and performance) is a nonstages model, because it does not identify a succession of phases or stages of the team's evolution, being instead multidimensional as it incorporates the interactions between the functions of the team, on the one hand, and the learning projects, on the other hand. The author concludes that teams can engage in four ways in the common learning activity, and these modes are to be "potential, but not necessary" [7]: (a) initiation - accepting the group project, setting action strategies; (b) solving technical problems - identifying means of documentation and learning, allocating resources, establishing procedures; (c) solving conflicts - pursuing and respecting the interests and core values of the group members; (d) implementing and performance - intense interactions in order to obtain the expected results, to achieve learning performance. Specifically, the TIP theory shows that there is an implicit path for a team evolution between the beginning and the end of a project, which is the most satisfying course or one that requires the least effort.

Continuing the work of forerunners, the researchers G.R. Bushe and G.H. Coetzer [8] are trying to create a comprehensive model of team evolution, in terms of efficiency, including all phases earlier mentioned by other researchers. Thus, Bushe and Coetzer describe two major milestones in team development towards performance: (a) acceptance of membership; (b) demonstrating the competence of the team. The existence of the first phase in solving learning tasks is motivated by the fact that, until members show psychological affiliation, there is no team, even if it is officially constituted. People who are part of a team have personal needs and goals, and it is natural to first assess to what extent the team can meet their expectations. It is time for intense psychological process: observation, knowledge, kneading, reflection, acceptance, revolt, conflict, self-analysis, etc. This phase is considered to be completed when all members want to be part of that team and reach the psychological assumption of belonging, referring to the team with the term "we". In the second stage the team structure is strengthened, which can ensure the proper distribution of learning tasks, the coordination of ideas and actions, the team members being centred on the fulfilment of responsibilities.

\section{A unifying theoretical model of the team development}

A theoretical unifying model of team evolution has been outlined over two decades by Susan Wheelan, the author of numerous studies in the field and the creator of a research tool named Group Development Questionnaire [9]. Wheelan's theoretical model can be considered to be stages and non-stages at the same time, as the evolution of a team appears to be linear 
on the axis of time, but in reality it is about pulsating growth until a downward sequence is reached. The life of teams in learning organizations passes through some psychosocial stages similar to those of a human being: the stage of formation (childhood), characterized by dependence on other entities; stage of rebellion (adolescence); the stage of self-confidence (youth); stage of creativity, dedicated work and performance (maturity); the stage of gradual disengagement and decline (old age). The model describes four stages in which the cycles of life can be recognized [10]: (a) dependency and inclusion (childhood) people rely on the leader and the more experienced members of the group to give them directions; sometimes engage in pseudo-learning, such as the exchange of impressions and stories about external activities or irrelevant topics for the task to be fulfilled; (b) counter-dependence and conflict (adolescence) - disagreements between members about learning objectives and procedures, conflicts generated by the need to establish a common set of values; (c) trust and structure (youth) - mutual trust among members, commitment to the group and willingness to cooperate; communication becomes more open and oriented towards learning tasks; more mature negotiations on roles, organization and procedures; members work to consolidate positive atmosphere; (d) work and productivity (maturity) - group members concentrate most of their energy on learning tasks; (e) disengagement (old age) - obtaining the learning outcomes, expressing mutual appreciation of the members and sharing the impressions left by the common learning experience.

\section{Punctuated equilibrium model}

American researcher Connie Gersick [11] proposes a theoretical model with very clear applications in knowledge-based organizations. In contrast to the previous approaches of the specialists, the author considers that the groups do not go from a lower stage to a higher stage of existence or functioning, but go through stages in which they exhibit other types of intellectual behaviours, as valuable for the fulfilment of the final goal of learning. The author starts from the premise that any work on a project involves learning and is carried out over a well-established time period, between the time when the team is set up and the project deadline. The author configures the theoretical model of the punctuated equilibrium, explaining that the activities of a learning team are influenced (interrupted, affected or modified) by two crucial moments on the temporal axis: the first working group meeting and the transition moment located exactly at the middle of the activity.

(a) First meeting is a neuralgic point in team dynamics. Despite being short, it is considered decisive because all exchanges of information, assumptions, views, action patterns that crystallize on this occasion will govern the first half of the lifetime of the learning team. Depending on what is concluded at the end of the first meeting, the team will address learning in a particular way, which will last for a longer time, inertial. Usually, in the first half of the learning time, the group's speed of advancement relative to the level to be reached in the end is low and the progress is insignificant.

(b) The second neuralgic point is located at the middle of the period of time allocated to the project (for fulfilling the learning goals), and is under the sign of the transition to something else and radical changes. Changes happen suddenly, in an avalanche and manifest themselves by abandoning the previous learning style, habits or patterns. These changes may be due to the intervention of outsiders (teachers, managers, stakeholders) or due to the emergence and consolidation within the group of a new perspective that makes possible significant progress towards fulfilling the task. The events that take place in these transition times, the evolution of the relations within the group and the 
interactions with the external environment lead to the shaping of a new vision and the drawing up of a new action plan, preparing the second period of activity of the group, with an essential role in success achieving. The implementation of the new approach to the learning tasks leads the team to a second inertial period, in which plans are implemented and the team works constantly. This phase culminates in the final meeting of the team members, characterized by hyperactivity and an increased interest in feedback provided by people outside the team.

A very interesting finding of the above mentioned study is that the transition moment always occurs precisely in the middle of the time allocated to the project, regardless of its duration, its field of study or the typology of the groups. Passing through the two phases of activity is not characterized by Gersick to represent qualitative progress of the team, but a change.

In summary, the Gersick model describes the dynamics of the activity of a team that learns to achieve a project, using the syntax of the punctuated equilibrium, thus: in the first half of the time the learning and realization of the project is balanced and smooth; the moment of transition and strong imbalance occurs; in the second half of time, learning is again relatively balanced, but the team does something other than what it did in the first period. Evolution of the team can be graphically represented as in the following figure:

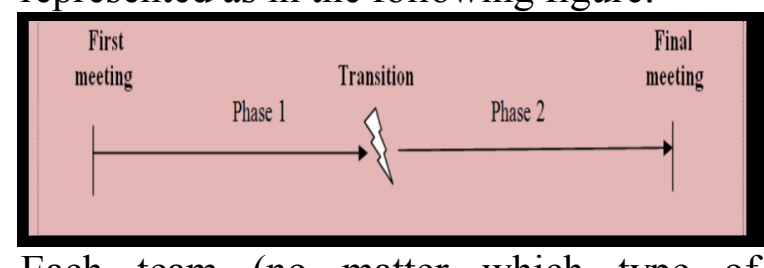

Each team (no matter which type of learning activity, in which field and at what level of complexity, whether it is a newly formed group or has long existed in that formula) functions successively undergoing periods of inertial equilibrium, punctually interrupted by sudden and intense changes and continued by other periods of inertial equilibrium, but in which other actions and other learning behaviours are taking place, depending on the changes that took place at the transition times.

\section{Final remarks}

Following the theoretical model created by Connie Gersick, we can highlight a series of implications that it has on the managers' activity and the management of the teams in order to efficiently fulfil the learning tasks:

- the first meeting must be prepared with the utmost care;

- expectations of progress should not be too high in the first part of the activity, as soon as people start learning;

- the mid-term transition must be handled carefully and skilfully, as an unnoticed problem or a mistaken decision could lead to failure. That is why it is necessary to evaluate all the ideas, proposals, problems that the members of the group are advancing, and even consulting some specialists outside the group or relevant bibliographic sources;

- until there is a major change in the way the training task is approached, the group will not make progress;

- the allocation of the necessary resources in the second phase of the activity is important for the actual implementation of the training plan;

- the deadline of learning must be respected, as a new time limit would not positively influence the transition from the middle, but only disturb the inner rhythm of the group.

\section{References}

[1] J. Proulx, Le travail en equipe, Presses de l'Universite de Quebec,1999, p.37

[2] W.G. Bennis, H.A. Shepard, "A theory of group development", Human Relations, 9(4)/1956, pp. 415-437. 
[3] http://buddhistpsychology.typepad.com/my-blog/-group-process-david-brazier.html\%20

[4] B.W. Tuckman, "Developmental sequence in small groups", Psychological Bulletin, 63(6)/1965, pp.384-39.

[5] B.M. Bass, E.C. Ryterband, Organizational Psychology, 2nd Edition, Allyn and Bacon Publications, Boston, 1979.

[6] J. McGrath, „Time, Interaction, and Performance (TIP). A Theory of Groups”, Small Group Research, 22(2)/1991, pp. 147-174.

[7] J. McGrath, op.cit., p.159.

[8] G.R. Bushe, G.H. Coetzer, „Group Development and Team Effectiveness”, The Journal of Applied Behavioral Science, 2(43)/2007, pp. 184-212

[9] https://gdqassoc.com/

[10] S. Wheelan, Creating effective teams. A guide for members and leaders, 3rd Edition, Thousand Oaks, Sage Publications, 2010.

[11] C. Gersick, „Time and transition in work teams: toward a new model of group development", The Academy of Management Journal, 1(31)/1988, pp.9-41. 